\title{
PENGARUH DUKUNGAN TEMAN SEBAYA TERHADAP PERENCANAAN KARIER SISWA
}

\author{
Heni Sulusyawati \\ Program Studi Bimbingan dan Konseling Fakultas Keguruan dan Ilmu Pendidikan Universitas Prof. Dr. Hazairin, SH \\ e-mai. Henisulusyawati9@gmail.com \\ https://orcid.org/0000-0002-1910-1392 \\ Juwanto \\ Program Studi Bimbingan dan Konseling Fakultas Keguruan dan Ilmu Pendidikan Universitas Prof. Dr. Hazairin, SH \\ e-mail. Mrjuanto1510@gmail.com \\ http://orcid.org/0000-0002-3506-7286
}

\begin{abstract}
Abstrak
Penelitian ini dilatar belakangi oleh masih ditemukannya siswa yang kebingungan dalam memilih jurusan memasuki Perguruan Tinggi. Tujuan penelitian ini untuk mendeskripsikan pengaruh dukungan sosial teman sebaya terhadap perencanaan karier siswa. Jenis penelitian ini merupakan penelitian deskriptif kualitatif, menggunakan pendekatan natual setting, yaitu lebih menekannkan pada penomena apa yang dialami oleh informan secara alamia. Penentuan informan dalam penelitian ini menggunakan metode purposive sampling. Pengumpulan data menggunakan teknik observasi, wawancara, dokumentasi, dan tri anggulasi. Analisis data menggunakan metode Miles Hurberman, yang mana Miles Huberman membagi 3 tahapan dalam Analisis data yaitu data reduction, data display, dan conclusion drawing/verification. Hasil penelitian menunjukkan bahwa terdapat pengaruh dukungan sosial teman sebaya terhadap perencanaan karier siswa, hal itu di tunjukkan dari dukungan emosional, dukungan penghargaan, and dukungan informasi.
\end{abstract}

Kata Kunci: Dukungan Sosial, Teman Sebaya, Perencanaan Karier

\begin{abstract}
This research was motivated by the finding of students who were still confused in choosing a major to enter higher education. The purpose of this study was to describe the effect of peer social support on student career planning. This type of research was a qualitative descriptive study. This study used a natural setting approach which placed more emphasis on what the informants experienced naturally. The determination of informants in this study used purposive sampling method. The data were collected by using observation, interview, documentation, and triangulation techniques. The data analysis used Miles Hurberman method. This method divided 3 stages in data analysis namely data reduction, display data, and conclusion drawing / verification. The results showed that there was an effect of peer social support on student career planning, it was shown from emotional support, appreciation support, and information support.
\end{abstract}

Kata Kunci: Social Support, Peers, Career Planning

\section{PENDAHULUAN}

Karier merupakan bagian yang penting untuk siswa, oleh karena itu siswa perlu untuk mempersiapkan perencanaan karier sejak dini. Yusuf (2002) mengemukakan karier bukan pekerjaan ataupun okupasi, akan tetapi karier merupakan serangkaian urutan yang terdapat dalam suatu pekerjaan seseorang. Perencanaan karier yang matang merupakan awal siswa dalam mencapai sukses dalam karier nantinya, maka dari itu diharapkan siswa agar dapat mempersiapkannya dengan baik pula, tentu dimulai dari siswa dapat menyelesaikan tugas-tugas perkembangan karier Super (dalam Sharf, 2010). menjelaskan proses perkembangan karier dapat dibagi dalam lima tahapan adalah 1) growth; meliputi tahap pengembangan sejak individu dilahirkan sampai sebelum usia individu 15 tahun, 2) exploration; meliputi usia individu mulai dari 15 tahun sampai 25 tahun. 3) establisment; meliputi usia individu berada pada 25-45 tahun, 4) maintenance; meliputi individu berada pada usia 45-65 tahun, dan 5) decline; meliputi usia individu berada pada 65 tahun, pada tahap ini individu sudah memasuki usia pensiun. 
Dibangku SMA belum terlambat untuk siswa mempersiapkan perencanaan karier dengan matang. Namun kenyataan dilapangan masih ditemukan siswa yang mengabaikan perencanaan karier, menganggap bahwa mempersiapkan perencanaan karier belum begitu penting, bahkan terdapat juga siswa menjawab pada saat di wawancara, nanti saja dipikirkan. Hasil Penelitian Sulusyawati, Yusuf, \& Daharnis (2017) menunjukkan bahwa perencanaan karier siswa secara keseluruhan berada pada kategori tinggi, namun dalam sub indikator perencanaan karier masih ada yang tergolong rendah, Artinya masih ada faktor lain yang mempengaruhi perencanaan karier siswa. Ahmad (2013) mengemukakan bahwa perencanaan karier tentu telah dimulai sejak seseorang berada di bangku sekolah, terutama pada tingkat SMA. Untuk mempersiapkan perencanaan karier yang matang tentu banyak faktor yang mempengaruhinya. Winkel \& Hastuti (2013) mengemukakan bahwa terdapat dua faktor yang dapat mempengaruhi perencanaan karier, yaitu faktor eksternal dan faktor internal. Faktor internal merupakan faktor yang yang terdapat dalam diri siswa, seperti nilai-nilai kehidupan, inteligensi, bakat khusus, minat, sifat-sifat, pengetahuan, keadaan jasmani. Faktor eksternal merupakan faktor yang dari luar diri siswa, seperti masyarakat, keadaan sosial ekonomi negara atau daerah, status sosial ekonomi keluarga, pengaruh keluarga besar maupun keluarga inti, pendidikan, pengaruh teman sebaya, dan tuntutan yang melekat pada jabatan. Selain dari pada itu, hasil penelitian Sulusyawati \& Juwanto (2020) menunjukkan bahwa adanya pengaruh faktor budaya melayu terdap perencanaan karier siswa. Hasil penelitian Malihah (2018) menunjukkan bebrapa faktor yang mempengaruhi perencanaan karier siswa yaitu faktor keluarga dengan persentase 96,25\%., faktor keterampilan dengan persentase $95 \%$, faktor sekolah $86,25 \%$, faktor teman sebaya $63,75 \%$, dan faktor belajar $41,5 \%$.

Herr, Cramer, \& Niles dalam Sulusyawati \& Sari (2019) Mengemukakan bahwa beberapa pertimbangan pentingnya perencanaan karier siswa pada tingkat SMA yaitu banyaknya siswa yang menyelesaikan pendidikan di tingkat SMA, mengutamakan pada penekanan bimbingan karier yang lebih konprehensif, melalui bimbingan karier diharapkan dapat memberikan cakupan pada pengembangan studi, teknik dalam mencari pekerjaan, beberapa keterampilan serta wawasan, dan keputusan karier yang akan dipilih oleh siswa sesuai dengan sekolah lanjutan yang akan dipilihnya. Selain dari pada itu pada masa ini siswa juga dihadapkan pada tekanan baik internal, maupun eksternal dalam mengambil keputusan memasuki perguruan tinggi, bekerja atau tidak bekerja, militer atau pegawai pemerintahan. Melalui penelitian ini peneliti akan mendeskripsikan data tentang pengaruh dukungan sosial teman sebaya terhadap perencanaan karier siswa.

\section{METODE}

Penelitian ini tergolong dalam penelitian kualitatif, menggunakan pendekatan natural setting yaitu lebih memahami kondisi atau fenomena apa yang sedang dialami oleh informan secara alamiah. Penentuan informan dalam penelitian ini menggunakan metode purposive sampling, yaitu siswa yang memiliki karakteristik kelompok teman sebaya. pengumpulan data menggunakan teknik observasi, wawancara, dokumentasi, dan trianggulasi. Teknik observasi dan wawancara yang digunakan yaitu observasi partisipatif dan wawancara tak berstruktur. Analisis data penelitian ini menggunakan model Miles dan Huberman, yaitu reduction, display, dan conclusion Sugiyono, (2018).

\section{HASIL PENELITIAN}

Berdasarkan hasil Analisi data maka dapat dikemukakan bahwa terdapat pengaruh dukungan teman sebaya terhadap perencanaaan karier siswa, secara rinci dapat dilihat pada tabel 1. Berukut:

Tabel. 1 Hasil Penelitian

\begin{tabular}{|c|c|c|}
\hline No & $\begin{array}{c}\text { Analisis } \\
\text { Data }\end{array}$ & Temuan Penelitian \\
\hline 1. & $\begin{array}{l}\text { Data } \\
\text { Reduction }\end{array}$ & $\begin{array}{l}\text { Berdasarkan hasil wawancara dan observasi } \\
\text { ditemukan kecenderungan siswa mengharapkan } \\
\text { dukungan antar teman sebaya, dalam } \\
\text { mempersiapkan perencanaan karier siswa. } \\
\text { Dukungan sosial ini begitu kuat adanya antar } \\
\text { teman, melebihi dukungan sosial dari keluarga } \\
\text { dan guru. Apabila anatar teman sebaya tidak } \\
\text { dapat memberikan atau menerima dukungan } \\
\text { sosial tersebut, akan membuat siswa menjadi } \\
\text { ada yang kurang dalam dirinya }\end{array}$ \\
\hline 2. & $\begin{array}{l}\text { Data } \\
\text { Display }\end{array}$ & $\begin{array}{l}\text { Berdasarkan Data Reduction, maka dapat } \\
\text { diketahui bahwa dukungan sosial yang } \\
\text { diharapkan oleh teman sebaya berupa rasa } \\
\text { empati, perhatian, memotivasi, dan memberikan } \\
\text { semangat antar teman sebaya, ketika siswa } \\
\text { memiliki ide atau gagasan, maka siswa } \\
\text { mengharapkan adanya penghargaan dari teman } \\
\text { sebaya terhadap ide-ide yang di kemukakannya. } \\
\text { Selain dari pada itu siswa juga membutuhkan } \\
\text { adanya informasi-informasi terkait dengan } \\
\text { perencanaan karier yang akan dipilihnya dari } \\
\text { teman sebaya }\end{array}$ \\
\hline 3. & $\begin{array}{l}\text { Conclusion } \\
\text { Drawing }\end{array}$ & $\begin{array}{l}\text { Berdasarkan Data Display, maka dapat } \\
\text { diketahui terdapat tiga dukungan sosial teman } \\
\text { sebaya yang dapat mempengaruhi perencanaan } \\
\text { karier, yaitu dukungan emosional, dukungan } \\
\text { penghargaaan, dan dukungan informasi }\end{array}$ \\
\hline
\end{tabular}

\section{PEMBAHASAN}




\section{Dukungan Emosinal}

Dukungan emosional merupakan salah satu pengaruh dukungan sosial teman sebaya yang mempengaruhi perencanaan karier siswa. Hal itu ditunjukkan dari rasa empati, perhatian, memotivasi, dan memberikan semngat memberikan semangat teman sebaya. antara siswa yang satu dengan siswa yang lainnya saling membutuhkan rasa tersebut. Apabila antar teman sebaya dapat memberikan rasa emapti, perhatian, memotivasi, dan memberikan semangat atar teman sebaya, maka siswa dapat melewati rintangan-rintangan dalam mempersiapkan perencanaan karier yang matang. Sebaliknya apabila antar teman sebaya tidak dapat memberikan rasa empati, perhatian, memotivasi, dan memberikan semngat, maka siswa begitu cepat menyerah, dan kurang dapat melewati kesulitan-atau rintangan dalam mempersiapkan perencanaan karier siswa. Jemini \& Gashi (2013) menunjukkan bahwa remaja yang tidak memperoleh dukungan sosial teman sebaya, maka siswa tersebut akan mengalami kesulitan-kesulitan dalam mengambil keputusan karier. Hasil penelitian Munawarah, dkk (2019) menunjukkan bahwa terdapat pengaruh positif yang signifikan antara dukungan teman sebaya terhadap regulasi diri, semakin tinggi dukungan teman sebaya, maka semakin tinggi pula regulasi diri remaja. Selanjutnya hasil penelitian Birama \& Nurkhin (2017) menunjukkan bahwa efikasi diri dapat memediadi pengaruh perencanaan karier maupun lingkungan teman sebaya terhadap minat melanjutkan ke perguruan tinggi. Berdasarkan ketiga hasil penelitian tersebut, dapat diambil kesimpulan bahwa dukungan teman sebaya memiliki pengaruh terhadap perencanaan karier siswa.

\section{Dukungan Penghargaan}

Selain dari dukungan secara emosional mempengaruhi perencanaan karier, dukungan penghargaan juga memberikan pengaruh terhadap perencanaan karier siswa. Hal itu ditunjukkan dari pernyataan setuju dari ide atau hal-hal yang dilakukan oleh siswa dalam mempersiapkan perencanaan karier yang matang. Penghargaaan yang diberikan oleh teman sebaya membuat siswa menjadi yakin atas ide-idenya dalam mempersiapkan perencanaan karier. Sebaliknya apabila siswa tidak mendapatkan dukungan penghargaan dari teman sebaya, maka akan berdampak atau dapat memberikan pengaruh juga terhadap persiapan perencanaan karier, karena adanya unsur siswa mengalami kebingungan dalam apakah ideide yang dimiliki dalam mempersiapkan perencanaan karier yang akan dipilih benar-benar mendukung atau sebaliknya. Handayani \& Abdullah (2018) menunjukkan bahwa dukungan teman sebaya memberikan dukungan sebesar $27,7 \%$ terhadap kematangan karier, sedangkan $70,3 \%$ diberikan oleh faktor lain. Sulusyawati \& Melati (2019) menunjukkan bahwa adaya pengaruh budaya rejang terhadap perencanaan karier. Selanjutnya hasil penelitian Muntamah \& Ariati (2017) menunjukkan bahwa adanya hubungan yang positif yang signifikan antara kelekatan terhadap teman sebaya dengan kematangan karier. Semakin aman kelekatan terhadap teman sebaya, maka kematangan karier akan semakin tinggi. Berdasarkan ketiga hasil penelitian tersebut, dapat simpulkan bahwa dukungan teman sebaya berpengaruh terhadap perencanaan karier siswa, tentunya mendukung hasil penelitian ini.

\section{Dukungan Informasi}

Selain dukungan emosional, dukungan penghargaan, terdapat juga pengaruh dukungan informasi terhadap perencanaan karier siswa. Hal tersebut ditunjukkan dari pemberian informasi dari teman sebaya tentang informasi yang berhubungan atau yang dibutuhkan oleh siswa. Tentunya informasi tentang persiapan perencanaan karier yang akan dipilih oleh siswa. Apabila dukungan informasi didapatkan oleh siswa dari teman sebaya, maka akan sangat membantu siswa dalam mempersiapkan perencanaan karier yang sesuai dengan potensi dirinya, sebaliknya apabila siswa tidak mendapatkan dukungan informasi, maka akan memberikan pengaruh pada siswa dalam mempersiapkan perencanaan karier yang matang kedepan. Sarafino (2007) Mengemukakan bentuk-bentuk dukungan sosial teman sebaya yaitu salah satunya dukungan informasi. Hasil penelitian Sasmita \& Rustika (2015) menunjukkan bahwa dukungan sosial teman sebaya berperan terhadap penyesuaian diri. Berdasarkan kedua hasil penelitian tersebut, maka dapat disimpulkan bahwa dukungan teman sebaya berpengaruh terhadap perencanaan karier siswa. Selanjutnya hasil penelitian Sulusyawati \& Syamsuddin (2021) menunjukkan bahwa komunikasi siswa yang kasar menyebabkan relasi pertemanan siswa di lembak menjadi terbatas, sehingga mempengaruhi perencanaan karier siswa. Hasil penelitian Munna \& Indrawati (2019) menunjukkan bahwa terdapat hubungan positif yang signifikan antara dukungan teman sebaya dengan kematangan karier pada siswa. Artinya semakin positif persepsi terhadap dukungan teman sebaya, maka semakin tinggi pula kematangan karier.

\section{PENUTUP}

\section{Simpulan}

Berdasarkan hasil dan pembahasan penelitian, maka dapat ditarik kesimpulan bahwa terdapat pengaruh dukungan teman sebaya terhadap perencanaan karier siswa. Hal tersebut ditunjukkan dari dukungan emosional, dukungan penghargaan, dan dukungan informasi yang diberikan oleh teman sebaya. Semakin baik dukungan yang diberikan oleh teman sebaya, baik dukungan emosional, 
dukungan penghargaan, maupun dukungan informasi, maka semakin matang perencanaan karier siswa.

\section{Saran}

Berdasarkan hasil temuan penelitian, maka dapat dimunculkan beberapa saran, meliputi: 1) bagi Guru Bimbingan dan Konseling/Konselor, agar dapat menjadikan pertimbangan hasil temuan penelitian ini dalam menyususn program khusnya di bidang karier. 2) bagi peneliti lanjutan, agar dapat mengembangkan penelitian sejenis, namun dengan latar belakang dan variabel yang berbeda, misalnya penelitian Kuantitatif atau PTBK.

\section{DAFTAR PUSTAKA}

Ahmad, R. 2013. Dasar-dasar Bimbingan dan Konseling. Padang: UNP Press.

Birama, B. C., \& Nurkhin, A. (2017). Peran Efikasi Diri Dalam Memediasi Pengaruh Perencanaan Karier Dan Lingkungan Teman Sebaya Terhadap Minat Melanjutkan Pendidikan Ke Perguruan Tinggi Siswa SMA Negeri 2 Slawi. Economic Education Analysis Journal, 6(1), 110-119.

Handayani, N., \& Abdullah, M. S. 2018. Dukungan Teman Sebaya dan Kematangan Karier Mahasiswa Tingkat Akhir. Jurnal Ilmiah Psikologi Terapan, 06 (01) 28-40.

Jemini, L. dan Gashi. 2013. Social support and Career Maturity of Kosovar Adolescents. Research and Education Callenges Toward The Future. ICRAE. ISSN: 2308-0825: 1-9

Sulusyawati, H., \& Syamsuddin, S. (2021). Budaya suku Lembak mempengaruhi perencanaan karier siswa. TERAPUTIK: Jurnal Bimbingan dan Konseling, 4(3), 460-470.

Sulusyawati, H., \& Juwanto, J. (2020). Malay Culture Effect on Career Planning Student SMA City 9 Bengkulu. Islamic Counseling: Jurnal Bimbingan dan Konseling Islam, 4(2), 237-246.

Sulusyawati, H., \& Sari, W. K. (2019). Potret Perencanaan Karier Siswa Budaya Rejang di SMA Negeri 9 Kota Bengkulu. Indonesian Journal of Guidance and Counseling: Theory and Application, 8(2), 114-118.

SULUSYAWATI, H., \& MELATI, M. (2019). PENGARUH BUDAYA REJANG TERHADAP PERENCANAAN KARIER SISWA DI SMA NEGERI 9 KOTA BENGKULU. Psikodidaktika: Jurnal Ilmu Pendidikan, Psikologi, Bimbingan dan Konseling, 4(2), 27-35.

Sulusyawati, H., Yusuf, A. M., \& Daharnis, D. (2017). Perencanaan karier siswa di SMA ditinjau dari status sosial ekonomi, jenis kelamin, dan jurusan. Bikotetik
(Bimbingan Dan Konseling: Teori Dan Praktik), 1(1), 8-14.

Sasmita, I. A. G. H. D., \& Rustika, I. M. (2015). Peran efikasi diri dan dukungan sosial teman sebaya terhadap penyesuaian diri mahasiswa tahun pertama Program Studi Pendidikan Dokter Fakultas Kedokteran Universitas Udayana. Jurnal Psikologi Udayana, 2(2), 280-289.

Sarafino, E.P. 2007. Health Psychology Biopsychosocial interaction (ed.6). New York: John Willey dan Sons, Inc.

Sharf, R.S. 2010. Applying Career Development Theory to Counseling. Pacific Grove, California. University of Delaware: Brooks/Cole Cengage Learning.

Sugiyono. 2018. Metode Penelitian Kualitatif dan R\&D. Bandung. Alfabeta.

Munawarah, M., Latipun, L., \& Amalia, S. (2019). Kontribusi dukungan teman sebaya terhadap regulasi diri pada remaja. PSIKOVIDYA, 23(2), 150-163.

Munna, A. C., \& Indrawati, E. S. (2019). HUBUNGAN ANTARA DUKUNGAN TEMAN SEBAYA DENGAN KEMATANGAN KARIER PADA SISWA KELAS XII SMK N 1 KENDAL (Doctoral dissertation, Undip).

Malihah, N. (2018). Faktor-Faktor yang Mempengaruhi Minat Siswa SMA Negeri 8 Kota Tangerang Selatan Terhadap Perencanaan Karier (Bachelor's thesis, Jakarta: FITK UIN Syarif Hidayatullah Jakarta).

Muntamah, M., \& Ariati, J. (2017). Hubungan antara Kelekatan terhadap Teman Sebaya dengan Kematangan Karir pada Siswa Kelas XI SMK Negeri 1 Trucuk Klaten. Empati, 5(4), 705-710.

Winkel, W. S., \& Hastuti, M. M. S. 2013. Bimbingan dan Konseling di Institusi Pendidikan. Yogyakarta: Media Abadi.

Yusuf, A. M. 2002. Kiat Sukses dalam Karier. Jakarta: Ghalia Indonesia. 